\title{
Intestinal Microbiome in Irritable Bowel Syndrome before and after Gut-Directed Hypnotherapy
}

\author{
Johannes Peter ${ }^{1, *}$, Camille Fournier ${ }^{1}$, Bettina Keip ${ }^{1}$, Nina Rittershaus ${ }^{1}$, \\ Nicola Stephanou-Rieser ${ }^{1}$, Marija Durdevic ${ }^{2}$, Clemens Dejaco $^{1}{ }^{\mathbb{D}}$, Maria Michalski $^{1}$ \\ and Gabriele Moser ${ }^{1}$ \\ 1 Division of Gastroenterology and Hepatology, Department of Internal Medicine III, \\ Medical University of Vienna, 1090 Wien, Austria; camille.4nier@gmail.com (C.F.); \\ bettina.keip@meduniwien.ac.at (B.K.); ninarittershaus@gmail.com (N.R.); \\ nicola.stephanou@hotmail.com (N.S.-R.); clemens.dejaco@meduniwien.ac.at (C.D.); \\ maria.michalski@medway.at (M.M.); gabriele.moser@meduniwien.ac.at (G.M.) \\ 2 Center of Medical Research, Medical University Graz, 8036 Graz, Austria; marija.durdevic@medunigraz.at \\ * Correspondence: johannes.peter@meduniwien.ac.at; Tel.: +43-140400-49700
}

Received: 31 October 2018; Accepted: 13 November 2018; Published: 16 November 2018

Abstract: Irritable bowel syndrome (IBS) is a disorder with brain-gut-microbiome alterations. Gut-directed hypnotherapy (GHT) has been shown to improve quality of life and symptoms in IBS. This therapy targets psychological coping, central nervous processing and brain-gut interaction. Studies have also demonstrated effects of hypnosis on intestinal transit and the mucosal immune system. So far, no study has examined the effect of GHT on the intestinal microbiome. This study aimed at examining microbial composition, IBS symptoms, and psychological distress before and after GHT. Methods: Fecal samples were collected from 38 IBS patients (Rome-III criteria, mean age 44 years, 27 female, 11 male, 22 diarrhea-dominant, 12 alternating-type and 4 constipation-dominant IBS) before and after 10 weekly group sessions of GHT. Assessments in psychological (perceived stress, PSQ; psychological distress, HADS-D; quality of life, visual analogue scales) and IBS symptom-related variables (IBS severity, IBS-SSS; single symptoms, visual analogue scales) were performed with validated questionnaires. Fecal samples underwent microbial 16S rRNA analyses (regions V1-2). Results: Microbial alpha diversity was stable before and after GHT (chao1 $2591 \pm 548$ vs. $2581 \pm 539$, $p=0.92$ ). No significant differences were found in relative bacterial abundances but trends of reduced abundance of Lachnospiraceae 32.18 (4.14-39.89) Median (Q1-Q3) vs. 28.11 (22.85; 35.55) and Firmicutes: Bacteroidetes ratio after GHT were observable. Significant reductions in symptom severity (323 (266-371) vs. $264(191-331), p=0.001)$ and psychological distress $17.0(12.6-21.8)$ vs. 12.0 (8.3-18.0), $p=0.001$, and increased well-being were found after GHT. Adequate relief after therapy was reported by $32(84 \%)$ patients. Conclusion: Reductions in IBS symptoms and psychological burden were observed after gut-directed hypnotherapy, but only small changes were found in intestinal microbiota composition. The findings suggest that hypnosis may act by central nervous impact and other factors largely independent from microbiota composition modulating the brain-gut axis, possibly alterations in vagus nerve functioning and microbiota metabolism.

Keywords: intestinal microbiome; irritable bowel syndrome; psychological intervention; hypnosis; psychological stress

\section{Introduction}

Irritable bowel syndrome (IBS) is a functional gastrointestinal disorder associated with abdominal pain and altered bowel habits affecting about $11 \%$ of the population worldwide [1]. It is currently 
conceptualized as a disorder of brain-gut interaction [2]. The bacterial microbiome has introduced a new perspective in brain-gut-axis communication and the understanding of IBS [3,4]. Insights from microbiome studies point to bidirectional influences between bacteria, host physiology and behavior [5-7], and a role of microbial factors in aberrant gut-brain axis signaling and IBS pathophysiology is strongly hypothesized. However, the evidence for gut microbial alterations in IBS is currently limited [8-10]. Alterations in psychobiological stress reactivity are also clearly implicated in IBS [11-13]. Data from our own and other research groups have shown associations between psychological stress and microbial factors [14-16], and animal models suggest a connection between stress-induced shifts in gut microbiota, visceral pain and altered brain-gut communication [17-19]. Presence of psychological distress and comorbidity are also a common clinical feature of IBS [20,21], and it is highly likely that psychological factors contribute to symptom generation and maintenance of the disorder [22,23].

A number of psychological treatments have therefore been developed for IBS, including Cognitive-Behavioral Therapy (CBT), hypnosis and other approaches [24,25]. Gut-directed hypnotherapy (GHT) for IBS was originally developed by Whorwell [26,27]. The documented benefits of GHT comprise direct reduction of IBS symptoms, as well as improvements in quality of life and wellbeing, non-colonic symptoms and decreased anxiety and depression [28-31]. Despite the clinical success of this therapy, relatively little is known about its pathways of action. Studies have reported evidence for reductions in dysfunctional cognition [32,33], alterations in cerebral pain processing [34], rectal sensitivity [35,36], and change in autonomous nervous system functioning [37].

An involvement of microbiota, or secondary effects of GHT via the brain-gut axis on microbiota seem also plausible for several reasons. Hypnosis elicits a state of relaxation, which is associated with a number of physiological changes, such as reduced heart rate, altered blood flow, metabolism, and brain activity [38,39]. It involves the Hypothalamic-Pituitary-Adrenal axis, which is linked to the gastrointestinal tract by endocrine pathways [40-42]. Reductions in systemic and colonic inflammatory factors after GHT were found in patients with ulcerative colitis [43]. Studies reported modulation of gastrointestinal physiology such as orocaecal transit time, gastric acid secretion and gastrocolonic response by hypnosis [44-46]. It remains unclear, if or to what extent these mechanisms are relevant for the success of the therapy [47], but they may contribute to microbial effects of hypnosis. Stool consistency and intestinal transit time were identified as markers of microbial composition [48,49], and studies have consistently reported decreases in diarrhea, but also bloating and abdominal pain after hypnotherapy. This leads to the hypothesis of microbial changes after GHT. The aim of this study was to examine the gut microbiome before and after GHT.

\section{Results}

\subsection{Sample Characteristics}

Data from 38 patients with IBS (Rome-III criteria, 27 women and 11 men) were analysed. The mean age in the sample was $44.05 \pm 14.48$ years (Mean \pm Standard Deviation). The majority of patients suffered from diarrhoea-predominant or mixed-type IBS. IBS symptom manifestation (as classified by the IBS-SSS $>300$ points [50]) was severe in most cases. A post-infectious history of onset ('PI-IBS') was present in $7(18 \%)$ patients. Eighteen $(48 \%)$ were in ongoing additional psychotherapy during the study. Antidepressants were taken by $7(18 \%)$, Mebeverine by $3(8 \%)$ and proton pump inhibitors by two (5\%). Domperidone, and Cholestyramine were taken by one patient respectively, and two patients reported the intake of a probiotic supplement. Intake of medication and probiotics was unchanged after GHT.

Baseline sample characteristics are given in Table 1. 
Table 1. Baseline sample characteristics.

\begin{tabular}{cc}
\hline IBS-D & $22(58 \%)$ \\
IBS-mix & $12(32 \%)$ \\
IBS-C & $4(10 \%)$ \\
Post-infectious IBS & $7(18 \%)$ \\
mild/moderate/severe IBS & $1(2 \%) / 12(32 \%) / 25(66 \%)$ \\
Disease duration & $7(3.38-14.25)$ \\
Presence of psychological distress & $25(66 \%)$ \\
\hline
\end{tabular}

Frequencies and percentages, or Median (Interquartile range).

\subsection{Intestinal Microbiome before and after Hypnosis}

\subsubsection{Alpha Diversity}

Alpha diversity before and after GHT was ascertained at a rarefaction depth of 20.000 sequences. There was no significant difference in alpha diversity, Chao1 amounted to $2591 \pm 548$ before and $2581 \pm 539$ (Mean \pm Standard Deviation) after therapy ( $p=0.92$, Mann-Whitney $U$-test and Monte-Carlo permutation).

\subsubsection{Bacterial Abundance}

Bacterial abundances on the family level showed some intraindividual variation before and after GHT, but were altogether largely equal over the two time points. Composition of the ten most abundant families before and after GHT is presented in Figure 1, relative abundances of all 58 bacterial families in the sample are visualized in Figure 2. A heatmap of genus abundances before and after hypnotherapy is provided in Supplementary File 1.

Testing of changes in bacterial abundance after GHT yielded changes in three bacterial families, and in 12 genera (Table 2). However, significances disappeared after controlling for multiple testing.

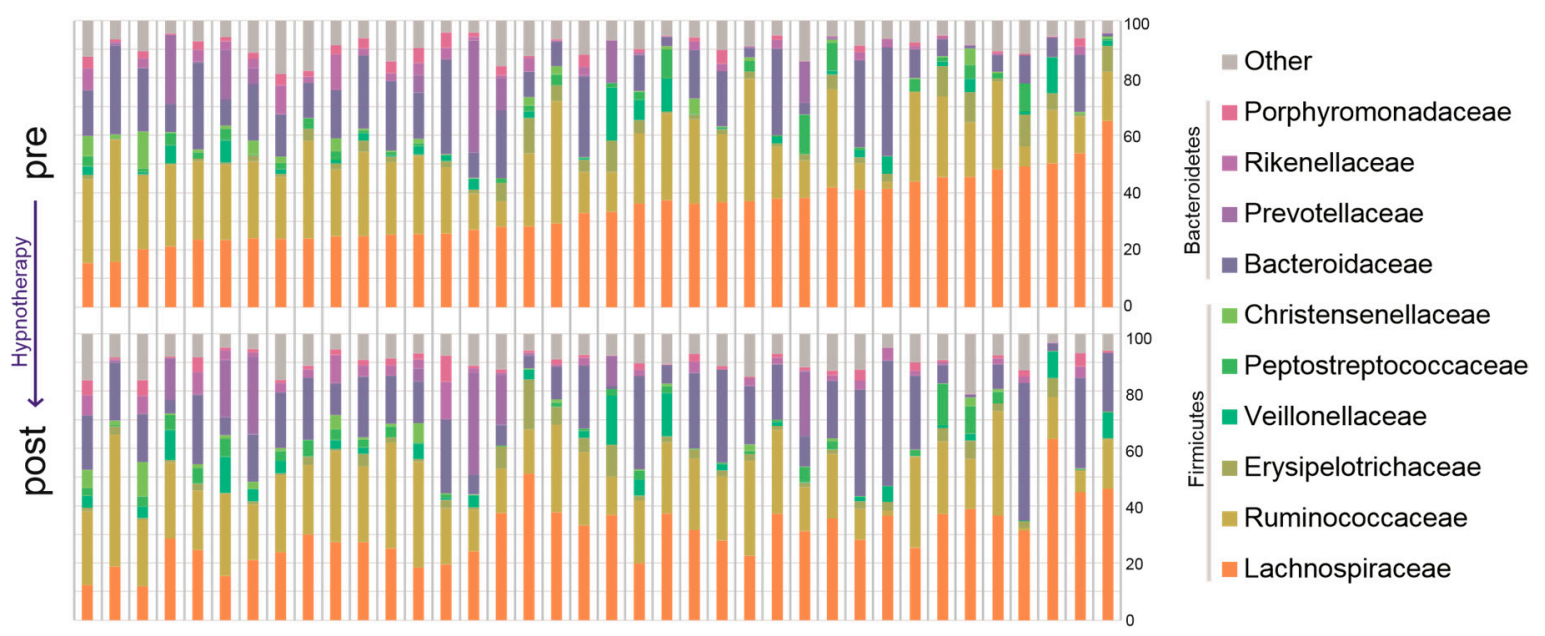

Figure 1. Relative abundance of the ten most prevalent bacterial families before and after gut-directed hypnotherapy (GHT). 


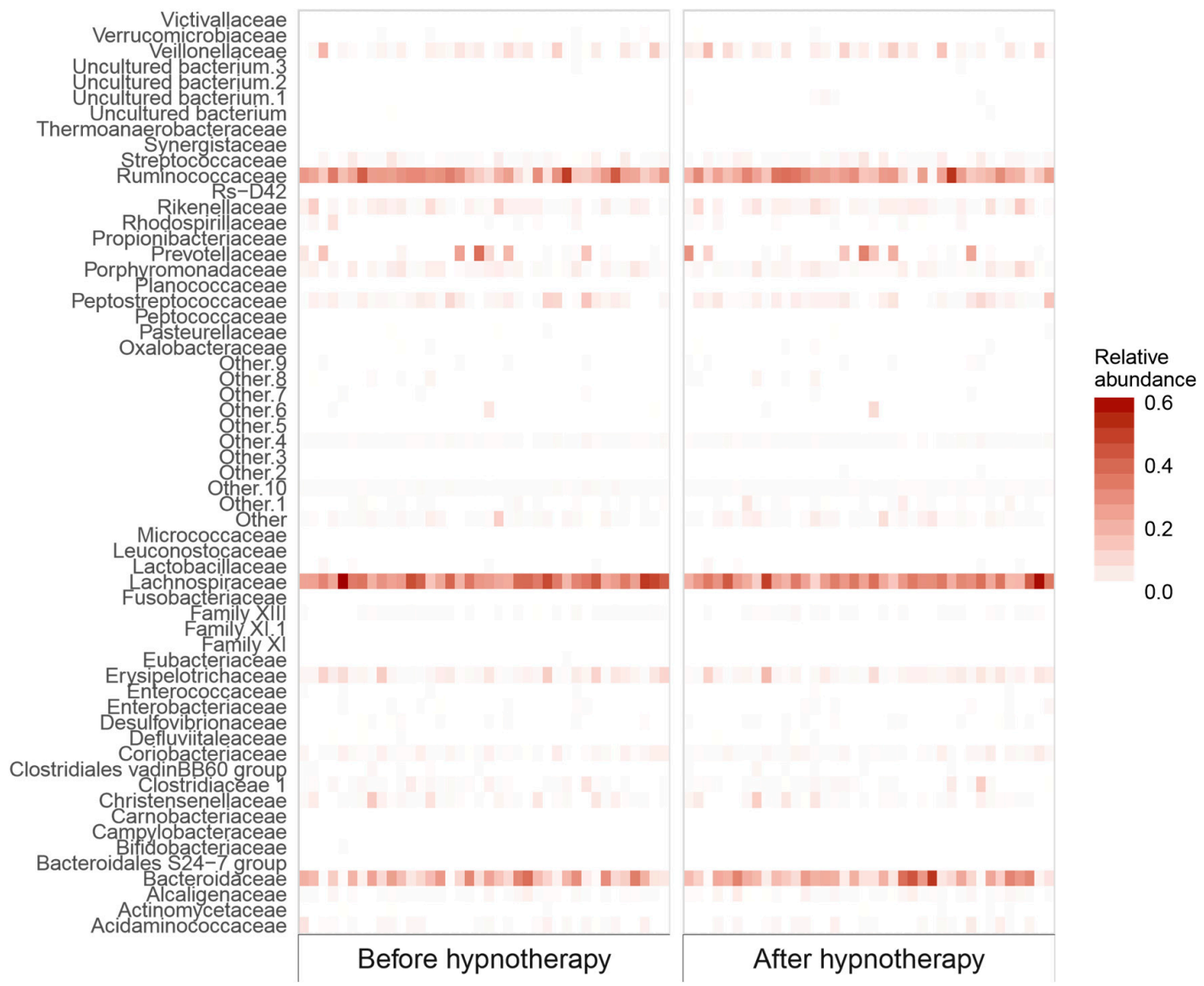

Figure 2. Heatmap of bacterial families before and after GHT.

The most pronounced absolute change in abundance was the reduction in the family Lachnospiraceae. In line with this, the Firmicutes:Bacteroidetes sank from 2.56 (1.77-6.45) before to 2.22 (1.50-3.68) after hypnosis, indicating a slight shift from gram-positives to gram-negative taxa, however the difference was not significant ( $p=0.34$, see Figure 3 ).

Table 2. Taxa with altered abundance before and after GHT.

\begin{tabular}{ccccc}
\hline Taxonomy & Before GHT & After GHT & $p$ & $q$ \\
\hline Families & & & & \\
Other Bacteroidetes & $0.0465(0.0092-0.1553)$ & $0.0771(0.0205-0.2472)$ & 0.0035 & 0.154 \\
Clostridiales XI & $0(0-0)$ & $0(0-0.0024)$ & 0.0053 & 0.154 \\
Lachnospiraceae & $32.18(24.14-39.89)$ & $28.11(22.85-35.55)$ & 0.0199 & 0.384 \\
Genera & & & & \\
Other Bacteroidetes & $0.0474(0.0093-0.1725)$ & $0.0568(0.0205-0.2211)$ & 0.0045 & 0.549 \\
Coprococcus 3 & $0.0359(0.0118-0.1134)$ & $0.0310(0.0102-0.0699)$ & 0.0057 & 0.549 \\
Uc Lachnospiraceae & $0.8217(0.4973-1.2215)$ & $0.8329(0.4190-1.1993)$ & 0.0149 & 0.743 \\
Clostridiales vadinBB60 group & $0(0-0.0074)$ & $0.0016(0-0.0094)$ & 0.0156 & 0.743 \\
Other Lachnospiraceae & $7.3539(5.0824-10.7166)$ & $6.5448(4.16041-9.1448)$ & 0.0263 & 0.743 \\
Lachnospiraceae UCG9 & $0(0-0.0090)$ & $0(0-0.0033)$ & 0.0328 & 0.743 \\
Intestinimonas & $0(0-0.0032)$ & $0.0014(0-0.0059)$ & 0.0358 & 0.743 \\
Anaerofustis & $0(0-0)$ & $0(0-0)$ & 0.0376 & 0.743 \\
Lachnospiraceae UCG10 & $0.0049(0-0.0251)$ & $0.0052(0-0.0142)$ & 0.0385 & 0.743 \\
Blautia & $5.3194(3.4527-7.3214)$ & $4.6071(2.6657-7.6441)$ & 0.0445 & 0.743 \\
Coprococcus 2 & $0(0-0.0016)$ & $0(0-0.0109)$ & 0.0458 & 0.743 \\
Eubacterium ventriosum group & $0.1553(0.0559-0.4382)$ & $0.1336(0.0344-0.2815)$ & 0.0464 & 0.743 \\
\hline
\end{tabular}

GHT: gut-directed hypnotherapy; relative abundances of taxa with changes $p<0.05$ in percent, Median [Q1-Q3]. $q$-values are FDR-corrected $p$-values. 


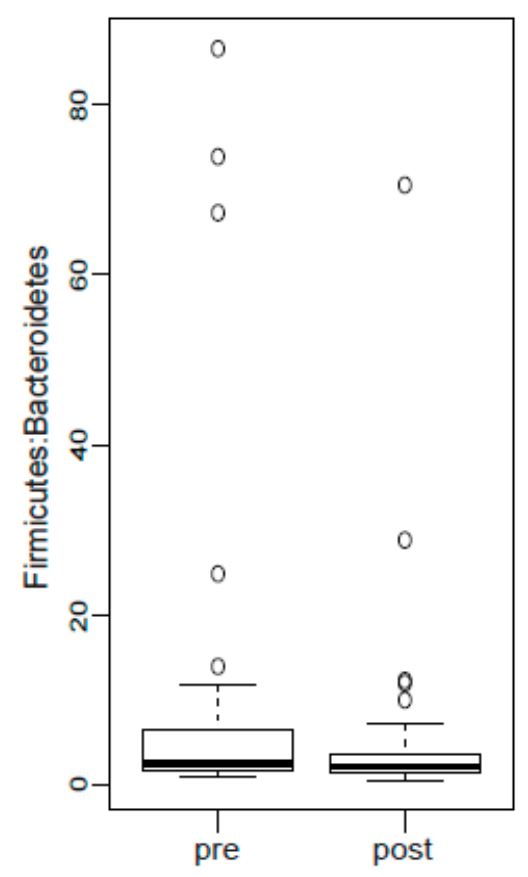

(a)

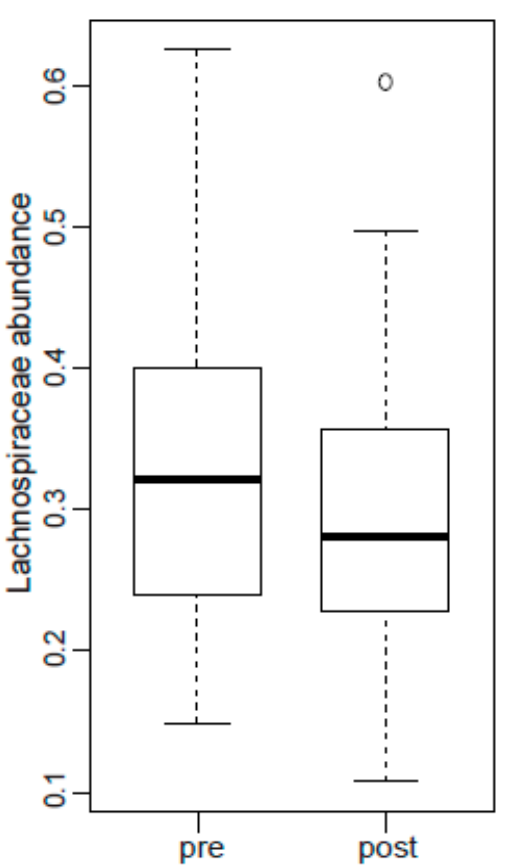

(b)

Figure 3. Boxplots of (a) Firmicutes:Bacteroidetes ratio and (b) abundance of Lachnospiraceae before and after hypnosis. None of the differences were significant.

Alterations with $p<0.05$ were also detected in 161 bacterial OTUs, but none remained significant after FDR correction. One hundred and one (63\%) of these OTUs were members of the family Lachnospiraceae, and 24 (15\%) of Ruminococcaceae (Supplementary File 2). With 1.86\%, the proportion of OTUs with relevant changes in abundance in comparison to the total number of OTUs seems small even before FDR correction.

\subsection{IBS Symptoms, Wellbeing and Psychological Stress}

Adequate relief from IBS symptoms after therapy was reported by 32 (84\%) patients. Interestingly, all of the seven patients with post-infectious history of onset (PI-IBS) reported adequate relief. Overall, IBS symptom severity decreased significantly after GHT (323 (266-371) Median [Interquartile range] vs. 264 (191-331), $q<0.01$. Reductions were also present in the IBS single symptoms bloating, abdominal pain, and diarrhea (all $\left.p^{\prime} \mathrm{s}<0.001\right)$, while constipation remained stable $(p=0.19$, Figure 4$)$.

Well-being (Visual analogue scales pertaining to general, physical and psychological well-being) increased from 105 (92-133) to 151 (122-194), while psychological distress decreased from 17 (12.6-21.8) points to 12 (8.3-18.0) points and stress perception fell from $0.570(0.478-0.643)$ to $0.425(0.278-0.600)$, all $p^{\prime}$ s $<0.01$, see Figure 5. 

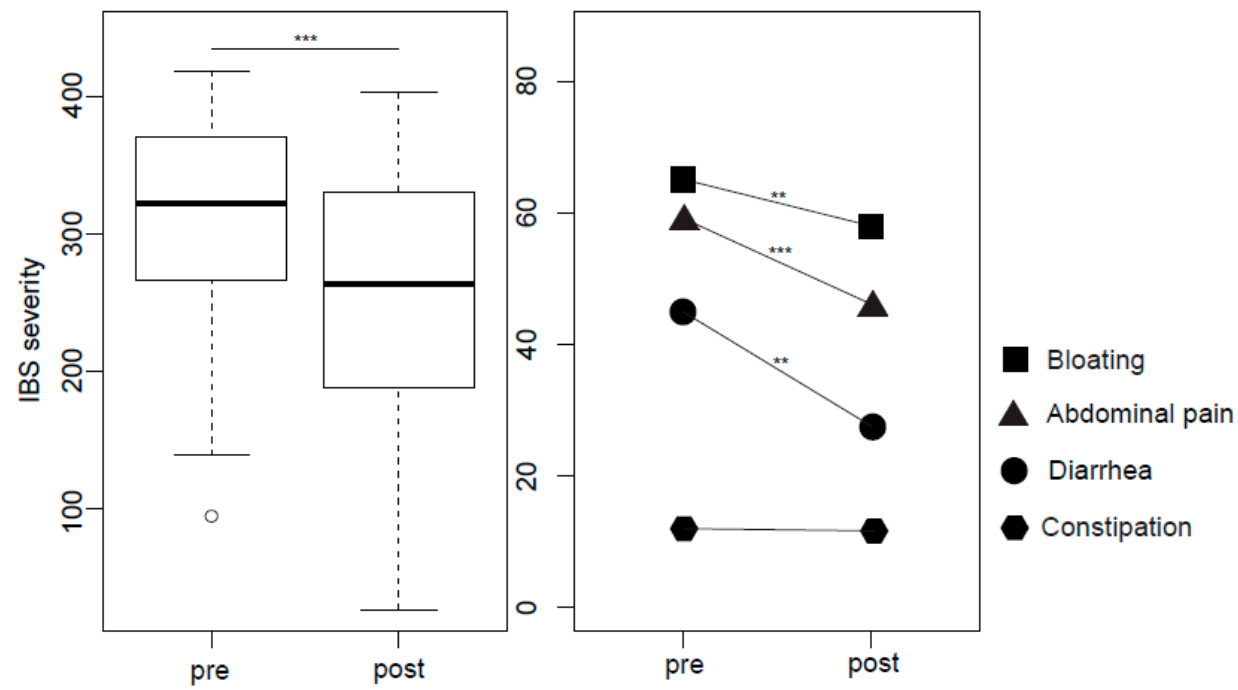

Figure 4. IBS (irritable bowel syndrome) severity (a) and IBS single symptoms (b) before and after GHT, ${ }^{* *} p<0.01, * * * p<0.001$.

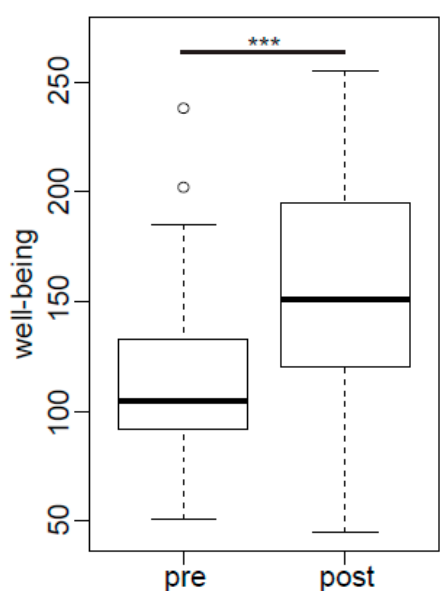

(a)

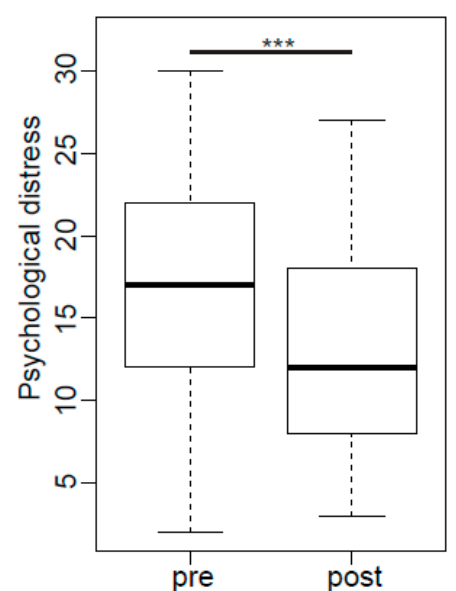

(b)

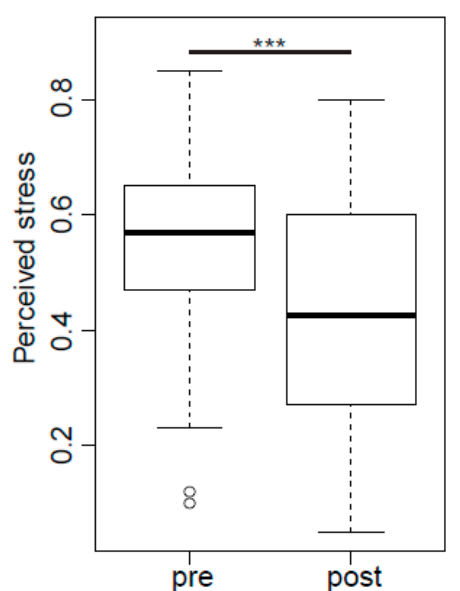

(c)

Figure 5. (a) well-being (VAS), (b) psychological distress (HADS), and (c) perceived stress before and after GHT, ${ }^{* * *} p<0.001$.

\subsection{Relationship between Clinical Improvement and Microbial Changes}

To detect microbial shifts possibly going along with the clinical improvements observed, changes in IBS severity pre-post intervention were correlated with pre-post intervention changes in abundance of bacterial genera. This yielded 17 correlations with Spearman's rho between 0.32 and 0.55 and $p$-values between 0.049 and $p<0.001$, however, none remained significant after FDR correction (Supplementary File 3). The strongest association was found in Oscillibacter, a member of the Ruminococcaceae family (Figure 6). 


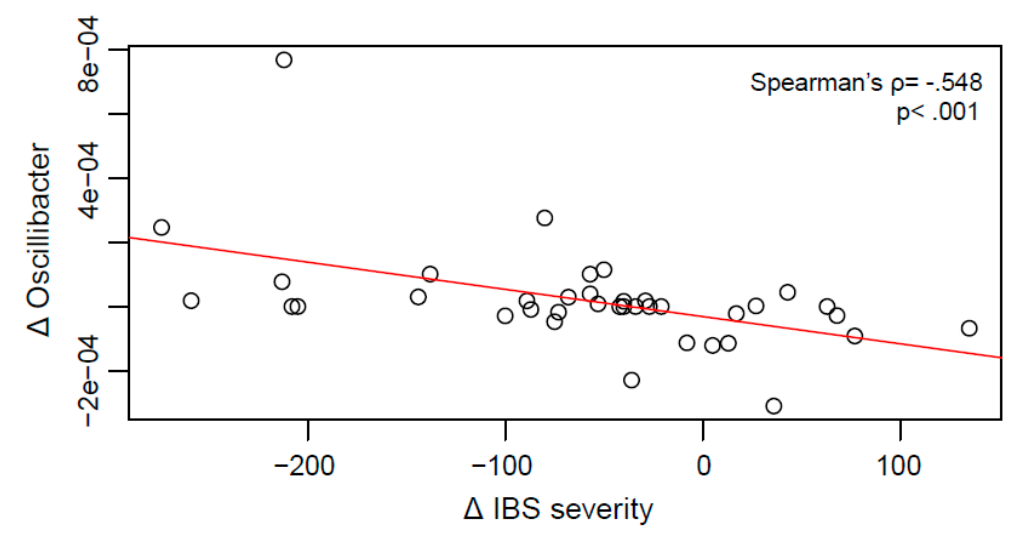

Figure 6. Scatterplot of the relation between changes in IBS severity and changes in abundance of the genus Oscillibacter pre-post GHT.

\subsection{Microbial Analyses of Sample Subgroups}

Since relevant microbial changes may have occurred in subgroups of patients during hypnosis, additional longitudinal analyses were undertaken exclusively in patients who reported adequate relief after therapy (subset of $n=32$ ), in patients with IBS with diarrhea (IBS-D, subset of $n=22$ ), and in patients with presence of significant psychological distress (subset of $n=25$ ). Microbial differences ( $p<0.05$ before controlling for multiple testing) after GHT were present in patients with adequate relief in 11 Genera, 5 families, and one Phylum; in those with IBS-D, in 5 Genera and 3 families; and in patients with psychological distress, in 5 Genera and 2 families. All significances disappeared after controlling for multiple testing. See detailed results in Supplementary File 4. For extensive cross-sectional subgroup analyses (performed with a slightly extended dataset inclusive of the patients analyzed here) see reference [16].

\subsection{Diet}

Complete dietary assessments over one week before and after hypnotherapy were available from $n=21$ patients, 17 patients had missing data in food frequency questionnaires. Baseline patterns of dietary intake were largely equal to those found in a representative national survey [51] with the exception of a markedly higher consumption of vegetables (exact values in Supplementary File 5). No significant changes, but trends of lower energy intake $(-12 \%)$, lower consumption of high-caloric foodstuff $(-62 \%)$ and higher consumption of fruit $(+49 \%)$, were found after hypnosis. For detailed results on diet see Supplementary File 5.

\section{Discussion}

This study examined the gut microbiome in irritable bowel syndrome before and after gut-directed hypnotherapy. While ground-braking discoveries in the microbiome field have introduced new perspectives in medical and behavioral sciences, and the brain-gut axis is currently a highly influential concept in neurogastroenterology and other disciplines [4,52,53], few studies have assessed the microbiome during or after behavioral interventions. This might be an important approach to elucidate brain-gut-microbiome interactions. To our knowledge, apart from one case study [54], the present study is the first to investigate the gut microbiome during a psychological intervention.

Important limitations of this study were the small sample size, and lack of a control group. Analyses of diet were hampered by incomplete data, and the expressiveness of microbial analyses was severely constrained by loss of power through repeated testing. An additional shortcoming has to be seen in ongoing additional psychotherapies during the study.

The microbial characteristics appeared to remain largely unchanged after the study intervention, gut-directed hypnotherapy. Bacterial diversity remained stable, and none of the changes in abundance 
were significant after controlling for multiple testing. Relatively consistent trends were observable in reduced Lachnospiraceae, one of the generally most abundant families in the human digestive tract [55]. Parallel tendencies of decreases were also present in the Firmicutes:Bacteroidetes ratio after hypnosis. The tendency of lowered energy intake after hypnosis, that became apparent in nutritional records, might be associated with this observation. A low Firmicutes:Bacteroidetes ratio was found to be associated with lean phenotypes, younger age, cardiovascular health and a balanced immune system and is generally considered beneficial for health [53,56-58]. The present findings are limited to trends, and replication studies are highly required to confirm a possible shift in the Firmicutes:Bacteroidetes ratio through hypnosis.

The genus Oscillibacter showed an association with changes in IBS symptom severity (yet not significant after controlling for multiple testing). Higher gut microbial abundances of Oscillibacter were previously identified in humans with depression [59]. Oscillibacter produce valeric acid, which resembles GABA and has been shown to bind the GABAa receptor [60,61]. An interaction of the metabolic products of Oscillibacter with the enteric and central nervous systems seems therefore plausible and deserves further investigation.

Overall, when examined on higher resolution levels (such as genus, or OTU level), the microbial differences observed between samples pre-post hypnosis seemed relatively unsystematic when taking into account the sheer number of comparisons/variables, and rather caused by random fluctuations than by distinct brain-to-gut modulations. This stands in contrast to the reported symptom improvements, especially reductions in diarrhea. These led to the hypothesis of microbial alterations, as stool consistency is regarded as a proxy for colon transit time, and has shown strong associations with microbiome composition and richness [62]. The majority of patients experienced marked reductions in general IBS severity and symptoms, and increased well-being after gut-directed hypnotherapy. Psychological distress and stress perception were reduced in most of the cases. These clinical improvements add to findings from previous studies [28,31]. The contrast between lack of microbial changes and improvements in IBS symptoms and psychological distress suggests that GHT acts on higher levels of the brain-gut axis, including psychological mechanisms [33], and modulation of processing of interoceptive stimuli $[34,63,64]$. However, further research on the precise mechanisms of therapeutic modulation of the brain-gut microbiota axis by hypnotherapy is highly required. Initial evidence has shown that hypnotherapy alters Autonomous Nervous functioning [37]. In this context, studies focusing on the role of the vagus nerve, which is an integral substrate of the brain-gut-axis and coordinates a number of motor, perceptive, inflammatory and gastrointestinal functions $[65,66]$ seem promising. With regard to the microbiome, given that in our study microbiota composition was largely unchanged by GHT, possible modulation of the microbiota function cannot be ruled out. Metabolomic studies are necessary to elucidate this aspect of therapeutic modulation of the brain-gut-microbiota axis.

\section{Materials and Methods}

\subsection{Recruitment}

The study was conducted at the University Hospital of Vienna, Outpatient Clinic for Psychosomatics at the Department of Gastroenterology and Hepatology, University Clinic of Internal Medicine III. It included patients with IBS diagnosed according to Rome III criteria, aged between 18 and 89, and refractory to other IBS therapies. Exclusion criteria were pregnancy, bowel surgery, mental retardation, insufficient knowledge of German, concomitant severe organic disease or Schizophrenia, Psychosis, Substance-Related Disorder or Panic Disorder, and antibiotic treatment within the month before stool collection. The time for patients to reach the hospital was not to be longer than $1 \mathrm{~h}$. Assessments were performed before and after gut-directed Hypnotherapy. Sixty-three patients were screened for eligibility, 53 were enrolled, 48 were included into cross-sectional analyses [16], and 45 participated in hypnosis. $N=38$ were included in the present analyses (see flowchart, 
Supplementary File 6). The study protocol was approved by the ethics committee of the Medical University of Vienna (ID: 1502/2014, (01/08/2014)) and registered (clinicaltrials.gov Identifier: NCT02536131). Informed consent was given by each participant. No financial or other incentives were offered for study participation.

\subsection{Intervention}

Gut-directed hypnotherapy was administered by GM and MM according to the Manchester protocol [27] in 10 weekly sessions ( $45 \mathrm{~min}$ ) in groups with 5-7 patients over a treatment period of 12 weeks at the university Hospital as in a previous study [28]. At the first session, participants were informed about the effects of hypnosis, and a compact disc (created by the therapist) was handed out at the third session for practicing at home on a daily basis (practicing was documented). Patients were asked not to change medication, intake of nutritional supplements and diet, and ongoing external psychotherapy during the study.

\section{3. $16 S$ rRNA Sequencing}

Stool samples were collected and frozen by patients, brought to the hospital and deep-frozen at $-80{ }^{\circ} \mathrm{C}$. DNA isolation, library preparation, and sequencing were then performed at the Graz University Center for Medical Research as described in Klymiuk et al., 2016 (82). Frozen stool samples were used for total DNA isolation by combination of mechanical and enzymatic lysis with the MagnaPure LC DNA Isolation Kit III (Bacteria, Fungi; Roche, Mannheim, Germany) according to manufacturer's instructions. Samples were bead-beaten for mechanical lysis at $6500 \mathrm{rpm}$ for $30 \mathrm{~s}$ twice in a MagNA Lyser (Roche). After incubation with lysozyme and Proteinase K, enzymes were deactivated at $95^{\circ} \mathrm{C}$ for $10 \mathrm{~min}$ and DNA purification was performed according to kit instructions. PCR amplification was performed with the target specific primers $27 \mathrm{f}$ and $357 \mathrm{r}$ and $2 \mu \mathrm{L}$ of total DNA extract were used for a $25 \mu \mathrm{L}$ PCR reaction in triplicates containing $1 \times$ Fast Start High Fidelity Buffer, 1.25 U High Fidelity Enzyme, $200 \mu \mathrm{M}$ dNTPs, $0.4 \mu \mathrm{M}$ bar-coded primers and PCR-grade water (Roche). The final library was quantified using a Quantus Fluorometer (Promega, Mannheim, Germany) and loaded to an Agilent 2100 Bioanalyzer (Agilent Technologies, Waldbronn, Germany) using a high-sensitivity DNA assay according to manufacturer's instructions for quality control. A 6 pM library run was performed on a MiSeqII desktop sequencer (Illumina, Eindhoven, The Netherlands) with 20\% PhiX control DNA. MiSeq paired-end raw sequence forward and reverse reads were subsequently merged using ea-utils v1.1.2 with standard settings, followed by a split library step from QIIME v1.9.1 and removal sequence reads shorter than 200 nucleotides, reads that contained ambiguous bases or reads with an average quality score of less than 30. Chimera were removed using USEARCH v6. against $97 \%$ clustered SILVA reference database (83). Operational taxonomic units (OTUs) were picked utilizing the QIIME open-reference pipeline to perform clustering steps at $97 \%$ sequence similarity, the taxonomy assignment with a UCLUST algorithm, alignment of reference sequences with pyNAST and generation of a phylogenetic tree with FastTree.

After filtering OTUs with less than 20 total counts and presence in less than 5 samples, the OTU table contained 8647 bacterial OTUs.

\subsection{Alpha Diversity Analyses}

Alpha diversity was analyzed at a rarefaction depth of 20,000 sequences using the observed species, Faith's phylogenetic diversity (PD) and estimated richness (chao1) metrics. Alpha comparisons among subgroups were performed by Mann-Whitney $U$-tests and 999 Monte Carlo permutations.

\subsection{Analyses of Bacterial Abundance}

Paired Wilcoxon tests of bacterial abundances were performed on Genus, Family, and Phylum level. Correction for multiple testing was by Benjamini Hochberg's False Discovery Rate (FDR). 


\subsection{Correlational Analyses}

Spearman correlations were calculated to test associations between change in relative abundance of microbial genera ( $\Delta$ abundance $=$ post-intervention abundance - pre-intervention abundance) and change in IBS severity (Scores of the IBS-SSS, $\Delta$ IBS severity $=$ post-intervention severity pre-intervention severity).

\subsection{Questionnaires}

IBS severity was assessed with the Irritable Bowel Syndrome-Severity Scoring System (IBS-SSS) [50], a questionnaire for clinical assessment of IBS symptom burden and severity. Values range between 0 and 500, with higher values representing higher symptom burden. Values were classified as mild (values ranging between 75-175), moderate (175-300), and severe IBS (300-500) as proposed. Sound reproducibility, sensitivity and specificity are reported for the German version [67], and the scale has been recommended repeatedly for assessment of IBS in methodological reviews [68,69].

Wellbeing was assessed by single analogue scales pertaining to general, physical and psychological wellbeing as in a former study [28]. The three scales $(0=$ very bad, up to $100=$ excellent $)$ were combined as a measure of wellbeing (0-300), Cronbach's alpha is 0.96 .

Psychological distress was assessed with the Hospital Anxiety and Depression Scale (German version, HADS-D), [70]. The two anxiety and depression scales (each with 7 items and a 4-step response set) are added together as a measure of psychological distress (scores 0-42). Reported internal consistency is Cronbach's $\alpha=0.80$. Presence of clinically relevant psychological distress was defined by depression scores greater than ten, or a combined score of 16 or more [71].

Perceived Stress was measured with the Perceived Stress Questionnaire, German version [72], an instrument assessing subjectively experienced stress independent of a specific and objective occasion with 20 items and 4-step response sets. Cronbach's $\alpha$ is $\geq 0.85$ for the overall score of the German version. Scores were linear transformed to values between 0 and 1 as appropriate.

The IBS symptoms abdominal pain, bloating, diarrhea, and constipation were assessed by single visual analogue scales ( 0 , not at all present-100, extremely pronounced) as in a previous study [28].

Success of therapy was further asked with a standardized question regarding adequate relief from IBS symptoms (yes/no) [54,68].

\subsection{Assessment of Diet}

Dietary intake was self-recorded by the participants of the study with a food frequency questionnaire (FFQ) over one week and averaged (divided by seven) to obtain the intake per day. Nutritional components were estimated (energy intake in kcal, carbohydrates, lipids, protein per day), and intake of food was summed up into categories (vegetables, fruit, cereals and dairy products, milk products, fish and foods containing unsaturated fats, and high-caloric food: Foods rich in fat and sugar, such as confectionery, chips, chocolate). Only complete FFQs over one week before and after GHT were included for analysis.

\subsection{Statistical Analyses}

Statistical analyses were conducted using QIIME [73], the bioinformatics platform Galaxy [74], and R [75]. Parameter-free testing was adopted as assumptions of normal distribution were violated. $p$-values were corrected by Bonferroni's method as default in QIIME or otherwise corrected by Benjamini \& Hochberg's method to control for the false discovery rate (FDR) and given as q values. The alpha level was set at 0.05 (two-sided) throughout all tests.

Supplementary Materials: Supplementary materials can be found at http:/ / www.mdpi.com/1422-0067/19/11/ 3619/s1.

Author Contributions: Conceptualization, G.M., and J.P.; Methodology, M.D., C.F., G.M., N.S.-R. and J.P.; Software, G.M., M.D., C.F.; Validation, B.K., N.R.; Hypnosis intervention: G.M., M.M. Formal Analysis, J.P., C.F., M.D., 
N.R., N.S.-R.; Investigation, G.M., M.M.; Resources, G.M., C.D.; Data Curation, J.P., C.F.; Writing-Original Draft Preparation, J.P., G.M., C.F.; Writing-Review \& Editing, G.M., J.P.; Visualization, J.P., C.F.; Supervision, G.M., C.D.; Project Administration, G.M., J.P.; Funding Acquisition, G.M., C.D., J.P.

Funding: This research was funded by Oesterreichische Nationalbank, Anniversary fund, grant number 16506 and the Oesterreichische Gesellschaft fuer Gastroenterologie und Hepatologie (OEGGH).

Acknowledgments: We wish to thank Christoph Högenauer for his recommendations for conceptualization of the study.

Conflicts of Interest: The authors declare having no conflict of interest. Unrelated to this study, Johannes Peter has received travel expenses from Yakult. Gabriele Moser has been on the Advisory Boards of Allergan and Almirall, she has received grants to the Medical University of Vienna by AbbVie, Vifor, Almirall, Merck, Falk, Yakult, Sanova, Danone, and she has been on the speakers bureaus for Falk, Peri Consulting, Henrich Communication, Milton Erickson Institut Austria, Wirtschaftskammer Austria, and Gebro. She has received payments for development of educational presentations by Ärztekammer Austria and travel expenses by Gebro and Falk. The funders had no role in the design of the study; in the collection, analyses, or interpretation of data; in the writing of the manuscript, and in the decision to publish the results.

\section{Abbreviations}

$\begin{array}{ll}\text { IBS } & \text { Irritable bowel syndrome } \\ \text { GHT } & \text { Gut-directed hypnotherapy } \\ \text { FDR } & \text { False Discovery Rate } \\ \text { OTU } & \text { Operational Taxonomic Unit } \\ \text { HADS } & \text { Hospital Anxiety and Depression Scale } \\ \text { VAS } & \text { Visual Analogue Scales } \\ \text { GABA } & \text { Gamma-aminobutyric acid }\end{array}$

\section{References}

1. Endo, Y.; Shoji, T.; Fukudo, S. Epidemiology of irritable bowel syndrome. Ann. Gastroenterol. 2015, 28, 158-159. [PubMed]

2. Drossman, D.A.; Hasler, W.L. Rome IV-Functional GI disorders: Disorders of gut-brain interaction. Gastroenterology 2016, 150, 1257-1261. [CrossRef] [PubMed]

3. Mayer, E.A.; Savidge, T.; Shulman, R.J. Brain-gut microbiome interactions and functional bowel disorders. Gastroenterology 2014, 146, 1500-1512. [CrossRef] [PubMed]

4. Mayer, E.A.; Knight, R.; Mazmanian, S.K.; Cryan, J.F.; Tillisch, K. Gut microbes and the brain: Paradigm shift in neuroscience. J. Neurosci. 2014, 34, 15490-15496. [CrossRef] [PubMed]

5. Kau, A.L.; Ahern, P.P.; Griffin, N.W.; Goodman, A.L.; Gordon, J.I. Human nutrition, the gut microbiome and the immune system. Nature 2011, 474, 327-336. [CrossRef] [PubMed]

6. Shreiner, A.B.; Kao, J.Y.; Young, V.B. The gut microbiome in health and in disease. Curr. Opin. Gastroenterol. 2015, 31, 69-75. [CrossRef] [PubMed]

7. Dinan, T.G.; Stilling, R.M.; Stanton, C.; Cryan, J.F. Collective unconscious: How gut microbes shape human behavior. J. Psychiatr. Res. 2015, 63, 1-9. [CrossRef] [PubMed]

8. Sundin, J.; Öhman, L.; Simren, M. Understanding the Gut Microbiota in Inflammatory and Functional Gastrointestinal Diseases. Psychosom. Med. 2017, 79, 857-867. [CrossRef] [PubMed]

9. Simrén, M.; Barbara, G.; Flint, H.J.; Spiegel, B.M.; Spiller, R.C.; Vanner, S.; Verdu, E.F.; Whorwell, P.J.; Zoetendal, E.G. Intestinal microbiota in functional bowel disorders: A Rome foundation report. Gut 2013, 62, 159-176. [CrossRef] [PubMed]

10. Rajilić-Stojanović, M.; Jonkers, D.M.; Salonen, A.; Hanevik, K.; Raes, J.; Jalanka, J.; De Vos, W.M.; Manichanh, C.; Golic, N.; Enck, P. Intestinal microbiota and diet in IBS: Causes, consequences, or epiphenomena? Am. J. Gastroenterol. 2015, 110, 278-287. [CrossRef] [PubMed]

11. Kennedy, P.; Cryan, J.; Quigley, E.; Dinan, T.; Clarke, G. A sustained hypothalamic-pituitary-adrenal axis response to acute psychosocial stress in irritable bowel syndrome. Psychol. Med. 2014, 44, 3123-3134. [CrossRef] [PubMed] 
12. Park, S.; Naliboff, B.; Shih, W.; Presson, A.; Videlock, E.; Ju, T.; Kilpatrick, L.; Gupta, A.; Mayer, E.; Chang, L. Resilience is decreased in irritable bowel syndrome and associated with symptoms and cortisol response. Neurogastroenterol. Motil. 2017, 30, e13155. [CrossRef] [PubMed]

13. Kano, M.; Muratsubaki, T.; Oudenhove, L.; Morishita, J.; Yoshizawa, M.; Kohno, K.; Yagihashi, M.; Tanaka, Y.; Mugikura, S.; Dupont, P. Altered brain and gut responses to corticotropin-releasing hormone (CRH) in patients with irritable bowel syndrome. Sci. Rep. 2017, 7, 12425. [CrossRef] [PubMed]

14. Jeffery, I.B.; O’Toole, P.W.; Ohman, L.; Claesson, M.J.; Deane, J.; Quigley, E.M. An irritable bowel syndrome subtype defined by species-specific alterations in faecal microbiota. Gut 2012, 61, 997-1006. [CrossRef] [PubMed]

15. Sundin, J.; Rangel, I.; Fuentes, S.; Heikamp-de Jong, I.; Hultgren-Hörnquist, E.; Vos, W.; Brummer, R.-J. Altered faecal and mucosal microbial composition in post-infectious irritable bowel syndrome patients correlates with mucosal lymphocyte phenotypes and psychological distress. Aliment. Pharmacol. Ther. 2015, 41, 342-351. [CrossRef] [PubMed]

16. Peter, J.; Fournier, C.; Durdevic, M.; Knoblich, L.; Keip, B.; Dejaco, C.; Trauner, M.; Moser, G. A microbial signature of psychological distress in irritable bowel syndrome. Psychosom. Med. 2018, 80, 698-709. [CrossRef] [PubMed]

17. Moloney, R.D.; Johnson, A.C.; O’Mahony, S.M.; Dinan, T.G.; Meerveld, G.V.; Cryan, J.F. Stress and the Microbiota-Gut-Brain Axis in Visceral Pain: Relevance to Irritable Bowel Syndrome. CNS Neurosci. Ther. 2016, 22, 102-117. [CrossRef] [PubMed]

18. Fourie, N.H.; Wang, D.; Abey, S.K.; Creekmore, A.L.; Hong, S.; Martin, C.G.; Wiley, J.W.; Henderson, W.A. Structural and functional alterations in the colonic microbiome of the rat in a model of stress induced irritable bowel syndrome. Gut Microbes 2017, 8, 33-45. [CrossRef] [PubMed]

19. Galley, J.D.; Nelson, M.C.; Yu, Z.; Dowd, S.E.; Walter, J.; Kumar, P.S.; Lyte, M.; Bailey, M.T. Exposure to a social stressor disrupts the community structure of the colonic mucosa-associated microbiota. BMC Microbiol. 2014, 14, 189. [CrossRef] [PubMed]

20. Fond, G.; Loundou, A.; Hamdani, N.; Boukouaci, W.; Dargel, A.; Oliveira, J.; Roger, M.; Tamouza, R.; Leboyer, M.; Boyer, L. Anxiety and depression comorbidities in irritable bowel syndrome (IBS): A systematic review and meta-analysis. Eur. Arch. Psychiatry Clin. Neurosci. 2014, 264, 651-660. [CrossRef] [PubMed]

21. Mayer, E.A.; Naliboff, B.D.; Chang, L.; Coutinho, S.V.V. Stress and irritable bowel syndrome. Am. J. Physiol. Gastrointest. Liver Physiol. 2001, 280, G519-G524. [CrossRef] [PubMed]

22. Kennedy, P.J.; Clarke, G.; Quigley, E.M.; Groeger, J.A.; Dinan, T.G.; Cryan, J.F. Gut memories: Towards a cognitive neurobiology of irritable bowel syndrome. Neurosci. Biobehav. Rev. 2012, 36, 310-340. [CrossRef] [PubMed]

23. Kano, M.; Endo, Y.; Fukudo, S. Association between alexithymia and functional gastrointestinal disorders. Front. Psychol. 2018, 9, 599. [CrossRef] [PubMed]

24. Thakur, E.; Holmes, H.; Lockhart, N.; Carty, J.; Ziadni, M.; Doherty, H.; Lackner, J.; Schubiner, H.; Lumley, M. Emotional awareness and expression training improves irritable bowel syndrome: A randomized controlled trial. Neurogastroenterol. Motil. 2017, 29, e13143. [CrossRef] [PubMed]

25. Ballou, S.; Keefer, L. Psychological interventions for irritable bowel syndrome and inflammatory bowel diseases. Clin. Transl. Gastroenterol. 2017, 8, e214. [CrossRef] [PubMed]

26. Whorwell, P.J.; Prior, A.; Faragher, E.B. Controlled trial of hypnotherapy in the treatment of severe irritable bowel syndrome. Lancet 1984, 324, 1232-1234. [CrossRef]

27. Gonsalkorale, W.M. Gut-directed hypnotherapy: The Manchester approach for treatment of irritable bowel syndrome. Int. J. Clin. Exp. Hypn. 2006, 54, 27-50. [CrossRef] [PubMed]

28. Moser, G.; Trägner, S.; Gajowniczek, E.E.; Mikulits, A.; Michalski, M.; Kazemi-Shirazi, L.; Kulnigg-Dabsch, S.; Führer, M.; Ponocny-Seliger, E.; Dejaco, C. Long-term success of GUT-directed group hypnosis for patients with refractory irritable bowel syndrome: A randomized controlled trial. Am. J. Gastroenterol. 2013, 108, 602-609. [CrossRef] [PubMed]

29. Whorwell, P.J. Hypnotherapy for irritable bowel syndrome: The response of colonic and noncolonic symptoms. J. Psychosom. Res. 2008, 64, 621-623. [CrossRef] [PubMed]

30. Lindfors, P.; Ljótsson, B.; Bjornsson, E.; Abrahamsson, H.; Simrén, M. Patient satisfaction after gut-directed hypnotherapy in irritable bowel syndrome. Neurogastroenterol. Motil. 2013, 25, 169-186. [CrossRef] [PubMed] 
31. Miller, V.; Carruthers, H.; Morris, J.; Hasan, S.; Archbold, S.; Whorwell, P. Hypnotherapy for irritable bowel syndrome: An audit of one thousand adult patients. Aliment. Pharmacol. Ther. 2015, 41, 844-855. [CrossRef] [PubMed]

32. Gonsalkorale, W.M.; Toner, B.B.; Whorwell, P.J. Cognitive change in patients undergoing hypnotherapy for irritable bowel syndrome. J. Psychosom. Res. 2004, 56, 271-278. [CrossRef]

33. Peter, J.; Tran, U.S.; Michalski, M.; Moser, G. The structure of resilience in irritable bowel syndrome and its improvement through hypnotherapy: Cross-sectional and prospective longitudinal data. PLoS ONE 2018. [CrossRef] [PubMed]

34. Lowén, M.B.; Mayer, E.A.; Sjöberg, M.; Tillisch, K.; Naliboff, B.; Labus, J.; Lundberg, P.; Ström, M.; Engström, M.; Walter, S.A. Effect of hypnotherapy and educational intervention on brain response to visceral stimulus in the irritable bowel syndrome. Aliment. Pharmacol. Ther. 2013, 37, 1184-1197. [CrossRef] [PubMed]

35. Prior, A.; Colgan, S.; Whorwell, P. Changes in rectal sensitivity after hypnotherapy in patients with irritable bowel syndrome. Gut 1990, 31, 896-898. [CrossRef] [PubMed]

36. Lea, R.; Houghton, L.; Calvert, E.; Larder, S.; Gonsalkorale, W.; Whelan, V.; Randles, J.; Cooper, P.; Cruickshanks, P.; Miller, V. Gut-focused hypnotherapy normalizes disordered rectal sensitivity in patients with irritable bowel syndrome. Aliment. Pharmacol. Ther. 2003, 17, 635-642. [CrossRef] [PubMed]

37. Palsson, O.S.; Turner, M.J.; Johnson, D.A.; Burnett, C.K.; Whitehead, W.E. Hypnosis treatment for severe irritable bowel syndrome: Investigation of mechanism and effects on symptoms. Dig. Dis. Sci. 2002, 47, 2605-2614. [CrossRef] [PubMed]

38. Benson, H.; Arns, P.A.; Hoffman, J.W. The relaxation response and hypnosis. Int. J. Clin. Exp. Hypn. 1981, 29, 259-270. [CrossRef]

39. Kekecs, Z.; Szekely, A.; Varga, K. Alterations in electrodermal activity and cardiac parasympathetic tone during hypnosis. Psychophysiology 2016, 53, 268-277. [CrossRef] [PubMed]

40. Wood, G.J.; Bughi, S.; Morrison, J.; Tanavoli, S.; Tanavoli, S.; Zadeh, H.H. Hypnosis, differential expression of cytokines by T-cell subsets, and the hypothalamo-pituitary-adrenal axis. Am. J. Clin. Hypn. 2003, 45, 179-196. [CrossRef] [PubMed]

41. Tache, Y.; Larauche, M.; Yuan, P.-Q.; Million, M. Brain and gut CRF signaling: Biological actions and role in the gastrointestinal tract. Curr. Mol. Pharmacol. 2018, 11, 51-71. [CrossRef] [PubMed]

42. Bhatia, V.; Tandon, R.K. Stress and the gastrointestinal tract. J. Gastroenterol. Hepatol. 2005, 20, 332-339. [CrossRef] [PubMed]

43. Mawdsley, J.E.; Jenkins, D.G.; Macey, M.G.; Langmead, L.; Rampton, D.S. The effect of hypnosis on systemic and rectal mucosal measures of inflammation in ulcerative colitis. Am. J. Gastroenterol. 2008, 103, 1460-1469. [CrossRef] [PubMed]

44. Beaugerie, L.; Burger, A.; Cadranel, J.; Lamy, P.; Gendre, J.; Le Quintrec, Y. Modulation of orocaecal transit time by hypnosis. Gut 1991, 32, 393-394. [CrossRef] [PubMed]

45. Klein, K.B.; Spiegel, D. Modulation of gastric acid secretion by hypnosis. Gastroenterology 1989, 96, $1383-1387$. [CrossRef]

46. Simrén, M.; Ringström, G.; Björnsson, E.S.; Abrahamsson, H. Treatment with hypnotherapy reduces the sensory and motor component of the gastrocolonic response in irritable bowel syndrome. Psychosom. Med. 2004, 66, 233-238. [CrossRef] [PubMed]

47. Lindfors, P.; Törnblom, H.; Sadik, R.; Björnsson, E.S.; Abrahamsson, H.; Simrén, M. Effects on gastrointestinal transit and antroduodenojejunal manometry after gut-directed hypnotherapy in irritable bowel syndrome (IBS). Scand. J. Gastroenterol. 2012, 47, 1480-1487. [CrossRef] [PubMed]

48. Falony, G.; Joossens, M.; Vieira-Silva, S.; Wang, J.; Darzi, Y.; Faust, K.; Kurilshikov, A.; Bonder, M.J.; Valles-Colomer, M.; Vandeputte, D. Population-level analysis of gut microbiome variation. Science 2016, 352, 560-564. [CrossRef] [PubMed]

49. Roager, H.M.; Hansen, L.B.; Bahl, M.I.; Frandsen, H.L.; Carvalho, V.; Gøbel, R.J.; Dalgaard, M.D.; Plichta, D.R.; Sparholt, M.H.; Vestergaard, H. Colonic transit time is related to bacterial metabolism and mucosal turnover in the gut. Nat. Microbiol. 2016, 1, 16093. [CrossRef] [PubMed]

50. Francis, C.; Morris, J.; Whorwell, P. The irritable bowel severity scoring system: A simple method of monitoring irritable bowel syndrome and its progress. Aliment. Pharmacol. Ther. 1997, 11, 395-402. [CrossRef] [PubMed] 
51. Elmadfa, I.; Wagner, K. Oesterreichischer Ernaehrungsbericht; Universität Wien: Vienna, Austria, 2012.

52. Allen, A.P.; Dinan, T.G.; Clarke, G.; Cryan, J.F. A psychology of the human brain-gut-microbiome axis. Soc. Personal. Psychol. Compass 2017, 11, e12309. [CrossRef] [PubMed]

53. Nicholson, J.K.; Holmes, E.; Kinross, J.; Burcelin, R.; Gibson, G.; Jia, W.; Pettersson, S. Host-gut microbiota metabolic interactions. Science 2012, 336, 1262-1267. [CrossRef] [PubMed]

54. Schnorr, S.L.; Bachner, H.A. Focus: Microbiome: Integrative Therapies in Anxiety Treatment with Special Emphasis on the Gut Microbiome. Yale J. Boil. Med. 2016, 89, 397-422.

55. Meehan, C.J.; Beiko, R.G. A phylogenomic view of ecological specialization in the Lachnospiraceae, a family of digestive tract-associated bacteria. Genome Biol. Evol. 2014, 6, 703-713. [CrossRef] [PubMed]

56. Koliada, A.; Syzenko, G.; Moseiko, V.; Budovska, L.; Puchkov, K.; Perederiy, V.; Gavalko, Y.; Dorofeyev, A.; Romanenko, M.; Tkach, S. Association between body mass index and Firmicutes/Bacteroidetes ratio in an adult Ukrainian population. BMC Microbiol. 2017, 17, 120. [CrossRef] [PubMed]

57. Tang, W.W.; Kitai, T.; Hazen, S.L. Gut microbiota in cardiovascular health and disease. Circ. Res. 2017, 120, 1183-1196. [CrossRef] [PubMed]

58. Zeng, M.; Inohara, N.; Nuñez, G. Mechanisms of inflammation-driven bacterial dysbiosis in the gut. Mucosal Immunol. 2017, 10, 18. [CrossRef] [PubMed]

59. Naseribafrouei, A.; Hestad, K.; Avershina, E.; Sekelja, M.; Linløkken, A.; Wilson, R.; Rudi, K. Correlation between the human fecal microbiota and depression. Neurogastroenterol. Motil. 2014, 26, 1155-1162. [CrossRef] [PubMed]

60. Holzl, J.; Godau, P. Receptor bindings studies with Valeriana officinalis on the benzodiazepine receptor. Planta. Med 1989, 55, 642. [CrossRef]

61. Katano, Y.; Fujinami, S.; Kawakoshi, A.; Nakazawa, H.; Oji, S.; Iino, T.; Oguchi, A.; Ankai, A.; Fukui, S.; Terui, Y. Complete genome sequence of Oscillibacter valericigenes Sjm18-20 ${ }^{\mathrm{T}}\left(=\mathrm{NBRC} 101213^{\mathrm{T}}\right)$. Stand. Genom. Sci. 2012, 6, 406-414. [CrossRef] [PubMed]

62. Vandeputte, D.; Falony, G.; Vieira-Silva, S.; Tito, R.Y.; Joossens, M.; Raes, J. Stool consistency is strongly associated with gut microbiota richness and composition, enterotypes and bacterial growth rates. Gut 2016, 65, 57-62. [CrossRef] [PubMed]

63. Demertzi, A.; Vanhaudenhuyse, A.; Noirhomme, Q.; Faymonville, M.-E.; Laureys, S. Hypnosis modulates behavioural measures and subjective ratings about external and internal awareness. J. Physiol. Paris 2015, 109, 173-179. [CrossRef] [PubMed]

64. Jensen, M.P.; Patterson, D.R. Hypnotic approaches for chronic pain management: Clinical implications of recent research findings. Am. Psychol. 2014, 69, 167-177. [CrossRef] [PubMed]

65. Bonaz, B.; Bazin, T.; Pellissier, S. The Vagus Nerve at the Interface of the Microbiota-Gut-Brain Axis. Front. Neurosci. 2018, 12, 49. [CrossRef] [PubMed]

66. Breit, S.; Kupferberg, A.; Rogler, G.; Hasler, G. Vagus Nerve as Modulator of the Brain-Gut Axis in Psychiatric and inflammatory Disorders. Front. Psychiatry 2018, 9, 44. [CrossRef] [PubMed]

67. Betz, C.; Mannsdörfer, K.; Bischoff, S. Validation of the IBS-SSS. Z. Gastroenterol. 2013, 51, 1171-1176. [PubMed]

68. Spiegel, B.; Camilleri, M.; Bolus, R.; Andresen, V.; Chey, W.D.; Fehnel, S.; Mangel, A.; Talley, N.J.; Whitehead, W.E. Psychometric evaluation of patient-reported outcomes in irritable bowel syndrome randomized controlled trials: A Rome Foundation report. Gastroenterology 2009, 137, 1944-1953. [CrossRef] [PubMed]

69. Mujagic, Z.; Keszthelyi, D.; Aziz, Q.; Reinisch, W.; Quetglas, E.; De Leonardis, F.; Segerdahl, M.; Masclee, A. Systematic review: Instruments to assess abdominal pain in irritable bowel syndrome. Aliment. Pharmacol. Ther. 2015, 42, 1064-1081. [CrossRef] [PubMed]

70. Petermann, F. Hospital Anxiety and Depression Scale, Deutsche Version (HADS-D). Z. Klin. Psychol. Psychiatr. Psychother. 2015, 59, 251-253. [CrossRef]

71. Sellick, S.M.; Edwardson, A.D. Screening new cancer patients for psychological distress using the hospital anxiety and depression scale. Psychooncology 2007, 16, 534-542. [CrossRef] [PubMed]

72. Fliege, H.; Rose, M.; Arck, P.; Levenstein, S.; Klapp, B. Validierung des "Perceived Stress Questionnaire" (PSQ) an einer deutschen Stichprobe. Diagnostica 2001, 47, 142-152. [CrossRef] 
73. Caporaso, J.G.; Kuczynski, J.; Stombaugh, J.; Bittinger, K.; Bushman, F.D.; Costello, E.K. QIIME allows analysis of high-throughput community sequencing data. Nat. Methods 2010, 7, 335-336. [CrossRef] [PubMed]

74. Goecks, J.; Nekrutenko, A.; Taylor, J. Galaxy: A comprehensive approach for supporting accessible, reproducible, and transparent computational research in the life sciences. Genome Biol. 2010, 11, R86. [CrossRef] [PubMed]

75. R Core Team (RC Team). R: A Language and Environment for Statistical Computing; R Foundation for Statistical Computing: Vienna, Austria, 2013.

(c)

(C) 2018 by the authors. Licensee MDPI, Basel, Switzerland. This article is an open access article distributed under the terms and conditions of the Creative Commons Attribution (CC BY) license (http://creativecommons.org/licenses/by/4.0/). 